\title{
THE IMPLEMENTATION OF URBAN SUSTAINABILITY STRATEGIES: THEORETICAL AND METHODOLOGICAL IMPLICATIONS FOR RESEARCHING BEHAVIOUR CHANGE
}

\author{
D. MÜLLER-EIE \& L. BJØRNØ \\ Department of industrial economics, risk management and planning, University of Stavanger, Norway.
}

\begin{abstract}
Implementing urban sustainability strategies has proven to be difficult. This paper aims at developing a holistic understanding of the urban sustainability concept with the help of a conceptual model, as well as offering a framework for understanding and researching the implementation of urban sustainability strategies. Here, individual behaviour change is understood as one of the main objectives of such strategies.

Through a conceptual model, four types of opposing and sometimes contradictory relationships are identified: (1) between global aims and local implementation, (2) between institutional pressure and the behaviour of individuals, (3) between strategic measures and personal consequences and (4) between attitudes and behaviour. These relationships are discussed in order to illustrate stalling factors in urban sustainability implementation.

Looking at behaviour change as a major goal of urban sustainability implementation, several social and individual behavioural theories are reviewed in order to construct a holistic and a compound model of the dynamics of behavioural change. By revealing a dual implementation process, consisting of provision on one side and choice on the other, we demarcate several important aspects for realising and researching urban sustainability strategies and their effectiveness. A more holistic way of assessing and monitoring the implementation of urban sustainability strategies is also proposed. The paper argues that rather than looking at the changes in the urban population's behaviour as a result, we must view them as an internal and essential sub-concept of urban sustainability.
\end{abstract}

Keywords: adoption, behaviour change, diffusion of innovations, individual and collective behaviour, public travel, urban sustainability.

\section{INTRODUCTION}

In a conference paper presented at the Sustainable City 2014 conference in Siena, we proposed to view the concept of urban sustainability as a social innovation [1]. Our intention was to understand why the implementation of urban sustainability is slow and met with reluctance. By embracing the complexity and the many layers of the urban sustainability concept, we try to point out internal sub-concepts (e.g. sustainable transportation), as well as its relationship with other concepts (e.g. climate change, global economy, social equity). We claim that a lack of understanding of the bigger picture leads to professional fragmented implementation, and unwillingness amongst the general public to change their behaviour and lifestyles (e.g. less travel, less consumption, less energy use). In March 2015 another conference paper was submitted that reviews several behaviour change theories [2]. We find that by combining a holistic understanding of urban sustainability strategies and generating awareness for the high relevance of individual behaviour and its factors, it is possible to assess and monitor urban sustainability strategies from a different (more holistic) perspective.

Therefore, this paper discusses several critical moments regarding behavioural change and proposes a compound ideological and methodical set of factors in order to realise 
and research the implementation of urban sustainability strategies in concrete projects, as well as being able to assess and monitor the success of such projects.

\section{THE URBAN SUSTAINABILITY CONCEPT}

Urban sustainability is defined as a compound concept consisting of several sets and subsets of concepts, levels, strategies and actors: Globally (in terms of aims and objectives) urban sustainability is defined as a city's capacity to meet formal, functional, social, economic and cultural standards that enable its population to live well and thrive without negatively impacting on global environmental, social and economic conditions. Locally (strategically) urban sustainability can be described as the facilitation and coordination between formal and functional strategies, such as sustainable land use (compactness, intensity, density) and sustainable transportation as well as their integration, in addition to cyclic resource management. Furthermore, the implementation of urban sustainability depends on two concepts: the provision of sustainable infrastructure and policy by urban institutions and collective and individual sustainable behaviour by the urban population [1]. Structuring and thereby simplifying the concept of urban sustainability like this leads to a division into two arenas: the goals (meaning the intentions, aims and objectives of urban sustainability); and the more concrete implementation (in terms of means actors and effect) (Fig. 1).

Because the sustainable development emerged as the World Commission on Environment Development's response to global environmental, social and economic issues (WCED, 1989), the concept is often defined through the aim of achieving environmental balance, social justice and economic feasibility. Attempting to give these aims more substance, often the concrete objectives, such as reduction of air pollution $\left(\mathrm{CO}_{2}\right.$ emission), are described.

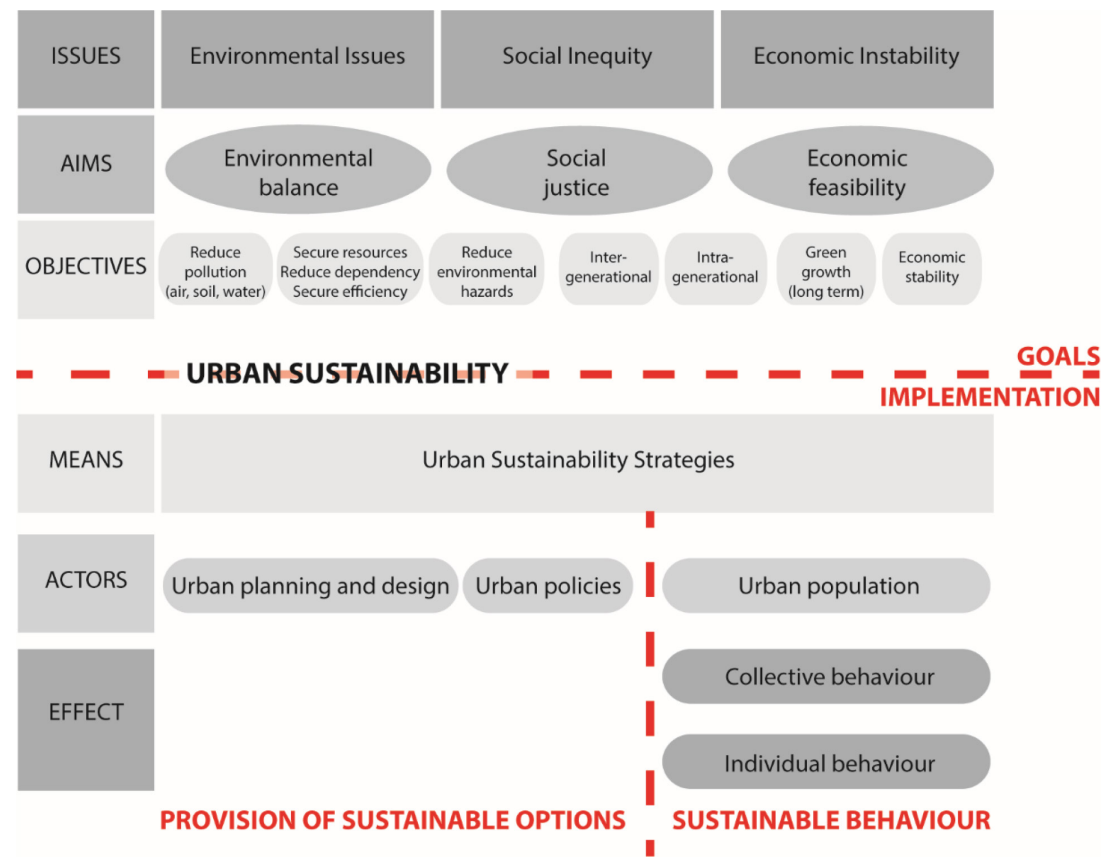

Figure 1: The urban sustainability concept, divided into goals and implementation (sustainable option + sustainable behaviour) (authors). 
However, a continued focus on these concepts keeps the discourse both rhetorically and ideologically in an arena that hinders concrete actions and may lead to empty consensus [3].

The focus of this paper lies on the implementation of urban sustainability. Here, strategic decisions are the main prerequisites for realising urban sustainability. This includes modal shift, transit-oriented development, compact built environment, high population densities, accessibility, 5-minute cities, etc. Different actors such as urban planners and designers, urban policy makers and - not least - the urban population locally implement these strategies. It is therefore important to regard the collective and individual behaviour as an important factor for realising urban sustainability strategies.

\section{THE INCONSISTENCIES OF URBAN SUSTAINABILITY}

Based on this simplified graphic model of urban sustainability, several areas of dissonance can be pointed out (Fig. 2). First, the non-conclusive relationship between global aim and local realisation; second, the non-communicative relationship between institutions and individual inhabitants; third, the con-compatible relationship between strategic/normative changes and individual desirability; and fourth, the non-commitive relationship between an individuals' attitude and behaviour. All four presented areas of conflict can help to explain the slow and reluctant process of implementing urban sustainability, and therefore need to be addressed when implementing urban sustainability strategies.

While we are looking at general areas of conflict within the urban sustainability concept, Anable et al. [4] have identified barriers for behaviour change. They range individual-subjective factors and particularly perceived behaviour control, self-efficacy, locus of control and denial among one of four powerful barriers to change. Other barriers to effective behaviour

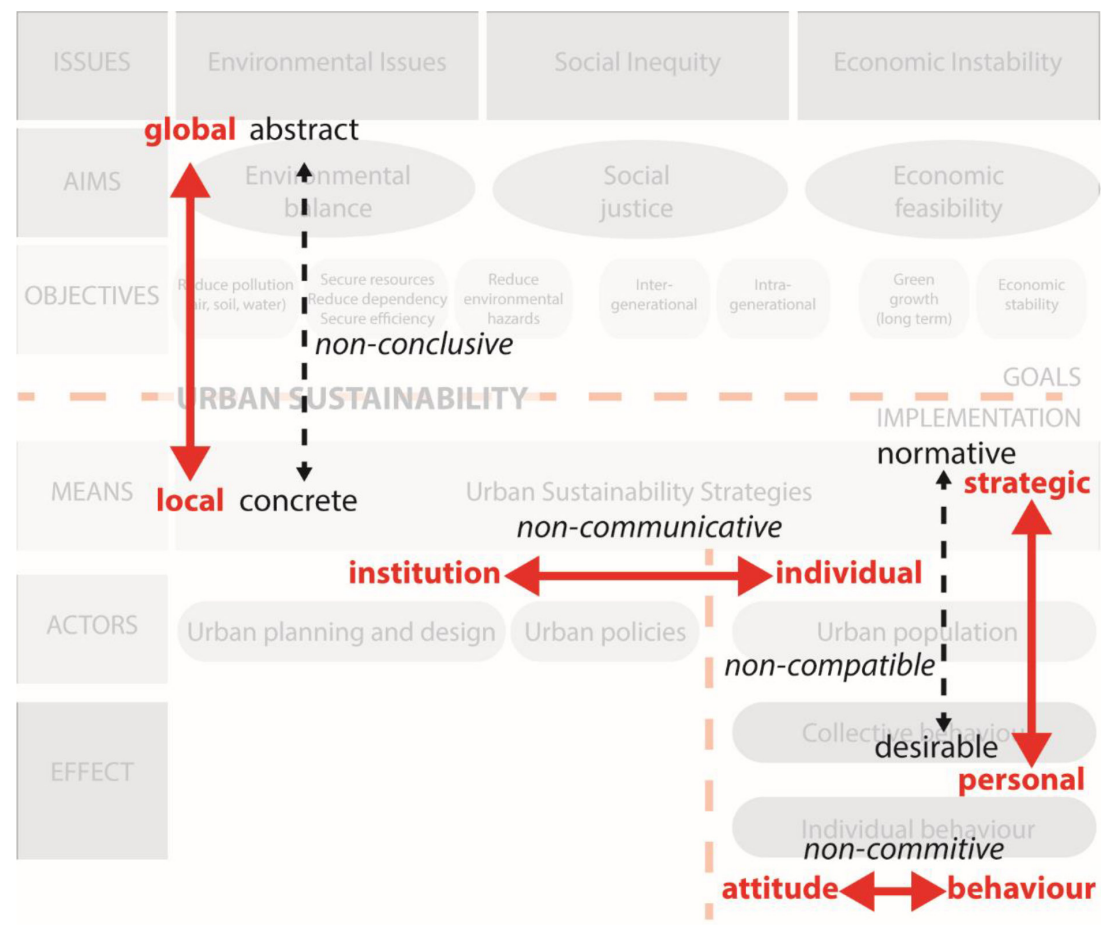

Figure 2: Areas of inconsistency within the urban sustainability concept (authors). 
change can be individual-objective (knowledge, habit), collective-subjective (social dilemma, shared norms, trust) or collective-objective (context, situation, communication) factors.

Above, a description of the conceptual inconsistencies as we see them is presented and exemplified.

3.1 Non-conclusive relationship: global and abstract aims vs. local and concrete implementation

There is a gap between the global and abstractly formulated goals and the concrete local materialisation of urban sustainability. Abstract formulations can lead to a false consensus in contrast to the contentious concrete measures that are proposed. For instance, people do not consider the global reduction of $\mathrm{CO}_{2}$ emissions when purchasing a new home. They also do not take the hypothetical relationship between building types and the reduction of demand for domestic energy and travel into consideration. There is also a lack of conclusive scientific research regarding the relationship and the effectiveness of the implemented strategies and their effect on the mentioned global aims [5-7]. This discrepancy and non- conclusiveness makes it difficult for institutions to commit to local sustainability strategies, and it makes it almost impossible for the general public to grasp and contribute to the urban sustainability discourse.

There is a discrepancy between the global evidence for climate change and necessity for local alleviation and the relationship between the two. This demands action in places and by individuals that have not necessarily felt the effects of the problem. Without the immediate feeling of inconvenience, humans are unlikely to make drastic changes. This makes it difficult to get support from the broad public and is partly what causes slow progress [8].

\subsection{Non-communicative relationship: institutional change vs. individual change}

Many different groups of actors and stakeholders are involved in the implementation of urban sustainability. Here, another gap exists between the institutions that are deciding about sustainable strategies and the people who make changes. When for instance introducing densification strategies, institutions rarely communicate the goals and reasons behind them, while individual cannot be expected to have adequate knowledge to interpret their environmental intentions. Strategies are often normative and unpopular, and stand in stark contrast to individual desirability. Urban policy operates with positive and negative incentives, while much of planning and design practice is based on the tacit assumption that the physical environment can manipulate and facilitate certain behaviour. This reveals that there is a lack of acknowledgement of behaviour change as a major goal of urban sustainability strategies, and that open and mutual communication between different stakeholders is a prerequisite for bettering the implementation process. Therefore, awareness raising, educational programs and explicit behaviour change programs can have a good effect in individual behaviour and lifestyle changes $[9,10]$.

This communication is often influenced by the use of rhetoric. While institutions often use prescriptive rhetoric, such as 'people' or 'they' need to use more public transport, it is in fact 'we' or 'us'. Such a rhetorical change can lead to institutions and facilitators to be forced to view themselves also as users, at the same time as the population might gain a greater feeling of ownership of such statements. 


\subsection{Non-compatible relationship: strategic and normative change vs. individual desirability}

Another area of conflict is the dissonance between strategic choice (e.g. regarding modal shift towards public and soft travel) and the way individuals make decisions based on personal interests and premises, often without knowledge about or concern for the environmental ramifications of their choices and actions. From an urban sustainability point of view, there is no arguing that a significant modal shift is beneficial, if not necessary. For the individual, however, it is different. While rationally most people are aware that it is beneficial for the 'greater good' if they decide to take the bus instead of the car, it is difficult to see personal benefits. Individual choice often rests on individual benefits and costs [11]. In this way, urban sustainability on a strategic level is not compatible with and does not incorporate urban individuals and their lifestyle choices. While a more sustainable lifestyle and travel behaviour can have advantageous, it is difficult to convey this to the public [12].

This contradiction between institutional rationality and individual emotional response is a problem in the implementation of urban sustainability strategies. While peoples' desires are individually understandable they are not collectively beneficial [13]. Thus, good urban sustainability strategies should (if possible) cater toward personal gain, such as shorter travel time, lower travel cost, more convenience, larger perceived control or better self-image.

\subsection{Non-committing relationship: attitudes vs. behaviour}

A last gap is the non-committing relationship between individual's attitudes and their behaviours, also known as the attitude-behaviour gap [4, 14]. While there might be a general positive attitude towards urban sustainability, this does not necessarily result in displaying the respective sustainable behaviour [15-17]. For instance, while people might be positive toward public and soft travel modes for commuting, they might still choose to car. Likewise, despite being positive toward the benefits of soft travel (such as the improvement of physiological and psychological health), people might still not choose to cycle or walk; due to other factors influencing their behaviour more dominantly. Knight describes this as being positive towards saving 'the environment' but sceptical towards interfering with 'my environment' [18]. Research shows that awareness and information are not sufficient in changing behaviour, but only in changing attitudes $[4,16]$, while the discussion below shows how information is a crucial first but not sufficient step in the adoption of more sustainable urban behaviour.

Based on this, it is not relevant to use attitude as a relevant predictor for behaviour, as has often been the case in empirical studies regarding behaviour change.

\section{THE COMPOUND MECHANISMS OF BEHAVIOURAL CHANGE}

The above discussion reveals that much of the concept of urban sustainability directly or indirectly aims at changing behaviour. While urban strategies, plans, designs and policies all aim at changing collective behaviour (Fig. 3), they often fail to incorporate what individual decision-making is really based upon: financial situation, life situations, age, values, beliefs, interests, emotions and habits. We argue that a truly holistic model of implementing urban sustainability, i.e. changing urban behaviour from unsustainable to sustainable, must be twofold, consisting of provision, consisting for instance of transport infrastructure, public transport service (coverage, frequency, prices), car incentives, etc., on one side and choice on the other (Fig. 4). Urban institutions need to admit to themselves and to the urban population 


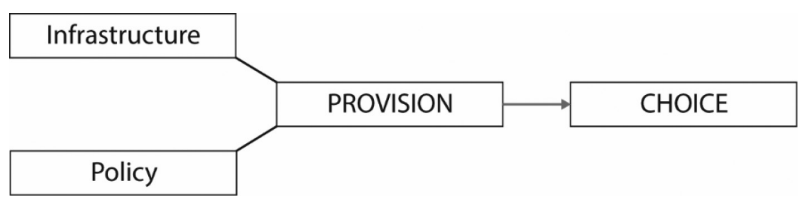

Figure 3: Traditional view of affecting behaviour in urban disciplines (authors).

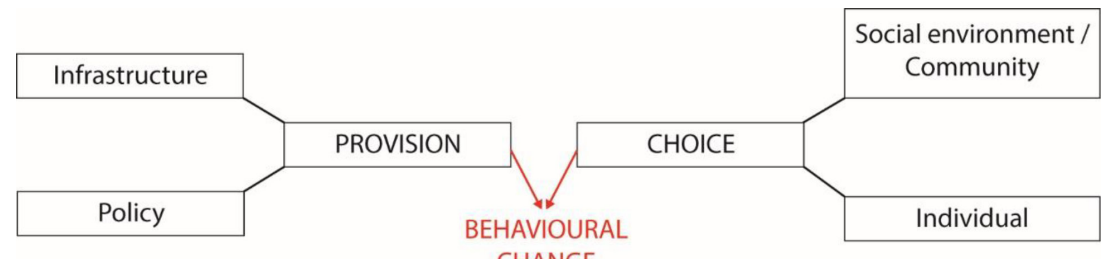

Figure 4: Proposed dynamic model of affecting behaviour through urban disciplines combined with social and personal attributes (authors).

in question that they are trying to change behaviour, while the urban population need to develop a sense of responsibility and accountability.

\subsection{Infrastructural aspects of behavioural change}

No doubt, necessary infrastructure is a prerequisite for behaviour change, i.e., modal change from car to public transport is not possible without viable public transport infrastructure in place. The same is true for domestic energy reduction through technological solutions such as low-energy housing, CHP, etc. This is not to say that people do not change without infrastructure, e.g. cycling and walking do not necessarily depend on infrastructure. However, when changing behaviour from unsustainable to sustainable, the physical framework must be in place for the individual to have a real alternative.

However, the meaning of infrastructure has often been overestimated. There is no guaranteed correlation between the provision of infrastructure and an increased use. It has for instance been shown that the provision of sustainable neighbourhood features not necessarily leads to more sustainable behaviour [19, 20], but rather mixed results. On the other hand, did sustainable features have an impact on awareness, social cohesion and contact [19], which supports the need for a holistic perspective which integrates social and community aspects.

\subsection{Policy aspects of behavioural change}

Urban policies are usually used in support of provided infrastructure. Currently, most aim directly at encouraging sustainable behaviour (subsidies in public transport for better service or pricing, tax breaks or preferred lanes for electrical cars, etc.) and discouraging from unsustainable behaviour (increased parking fees, road tax, road toll, etc.). While such positive and negative incentives can affect people's convenience or finance, there might not be a direct link with changing behaviour due to a lack of rational decision-making (see section 4.3). In addition, financial incentives only work in societies that are sensitive to financial change. In affluent population, financial incentives will have less of an impact [21]. 
Another aspect is participatory and inclusive processes. While policies provide for and often dictate inclusion and participation, those are often more informative and include only a small portion of the inhabitants. We therefore argue that actively including individuals should be addressed through community aspects and decision-making as discussed in section 4.3. If ideas about changing also emerge within the urban society itself, they will feel a greater sense of ownership of the idea and possible identify themselves with the new behaviour. As such, policies together with physical and infrastructural provision are a necessary but not sufficient step in achieving behavioural change.

\subsection{Socio-cultural aspects of behavioural change}

Choice, or the adoption of certain behaviour, is not only based on individual psychological aspects (see section 4.4), but also on the social and cultural environment the individual lives in.

Theories that support social decision-making are Social Capital theory [22] and the Diffusion of Innovation [23]. Interpersonal theories include Triandis' Theory of Interpersonal behaviour (TIB) [24] and Social Learning theory (SLT). For a full review see Anable et al. [4].

There is no doubt that community social and cultural aspects, such as norms, values, beliefs and moral, influence individual decision-making. These factors are often referred to as normative [25] or symbolic [4, 26, 27], since they are based on what the individual believes to be a good or the right choice as well as considering the meaning of their choice as it impacts on their social status and role. Further, some social theories (Norm Activation Theory [28] and Values-Beliefs-Norms Theory [29]) have described altruistic behaviour that is motivated by responsibility and obligation towards common welfare. Consequently, it is beneficial to take the role social groups and communities play whenever introducing infrastructural or policy change. This has for instance been studied in social behaviour change programs, for instance EcoTeams, which are found to be effective programs but generally work to isolated and small-scale [9].

Here, particularly communication seems to be a decisive factor. According to Rogers [23] diffusion theory, communication plays a strong role in spreading innovative ideas and it is defined by the limits of social interaction and time. This socio-dynamic process of diffusion of innovations can be related to using information in order to enhance awareness in urban sustainability [30]. While communication and information has previously been invalidated as sufficient ground for behaviour change [16], Rogers [23] presents knowledge as a critical first step in a five-stage process (knowledge, persuasion (positive or negative attitude), decision (acceptance or rejection), implementation (use) and confirmation). Furthermore, time is seen to be an important element in this process; both the time it takes for a member of the social system to adopt the innovation (individual) and the time it takes for the innovation to achieve a critical mass (collective). In order to achieve quicker adoption, quick diffusion of an innovation is essential. For instance, the adoption by high-status individuals of a social network as well as communication among homogeneous social groups as well as between heterogeneous social groups is discussed.

Integrating socio-cultural measures has so far received little attention within urban spatial and political disciplines, and we argue that processes such as social marketing [31] need to become an inherent part of introducing urban sustainability strategies, infrastructure and policies. 


\subsection{Personal-psychological aspects of behavioural change}

Drivers of urban behaviour (e.g. travel) have been thoroughly investigated [4, 16, 32], and repeatedly practical and rational drivers as strongest decision-making base have been invalidated [33] Instead, emotional and affective factors (such as freedom, control, pleasure, stress, enjoyment, relaxation, independence, etc.) have been promoted to play a decisive role [4]. In addition has the role of habitual behaviour and its resilience to change been investigated $[34,35]$.

Theories that investigate individual decision-making are amongst other the Deficit Model [36], the Rational Choice Theory and the Theory of Planned Behaviour (TPB) [37]. Here, rational factors, such as cost and benefit are decision basis. For a full review see Anable et al. [4].

However, often decisions are governed by emotions (affect) such as pride, happiness, satisfaction, excitement, pleasure, fear, worries, anger, stress or boredom [33, 38]. Based on their pleasure-oriented nature of such emotions they are often referred to as hedonic factors $[25,26]$. According to Owens and Drifill [16] price, awareness, trust, commitment, moral obligation, cultural norms, routines, social networks, fashion, comfort and convenience are all factors that impact individual behaviour. Therefore, in order to manipulate individual behaviour effectively, the sustainable choice must be the emotionally most appealing. This is particularly important, since individuals tend to decide in favour of their emotions over reason [33].

If changing individuals' behaviour and changing it fast is key for achieving urban sustainability, then social-cultural and possibly more important hedonic factors need to be taken into account. This may be in part through designing infrastructure, services and policy to appeal to these decision-making factors, as well as highlighting them through social marketing and public communication strategies.

\section{THEORETICAL AND METHODOLOGICAL IMPLICATIONS}

Based on the review above, we propose a stronger focus on the urban individuals and an incorporation of their decision-making and its factors into strategic approaches that aim at making cities more sustainable. Personal and psychological attributes need to be taken into account, as well as community aspects and the force of communication between social and cultural milieus (Fig. 5). In addition, the different actors implementing urban sustainability (i.e. institutions and individuals) have to engage in a mutual communication process in order to achieve a synergistic effect.

Thus, an integrated approach addressing the change of urban behaviour needs to incorporate infrastructure, policy, society and the individual. While this seems obvious, previous attempts at implementing urban sustainability strategies have mainly focused on urban infrastructure and policy. They rarely include individual behaviour, other than as a measure of monitoring the success or failure of said strategies. Based on this, and based on the possibilities that reveal themselves when integrating knowledge from other disciplines, we propose that urban sustainability must be viewed as an inherently anthropocentric concept, rather than issues revolving around infrastructure provision and policy introduction.

\subsection{Theoretical implications}

Ideologically, this means that the planning and design disciplines need to revisit their tacit hypothesis that the provision of the physical environment and political measures are 


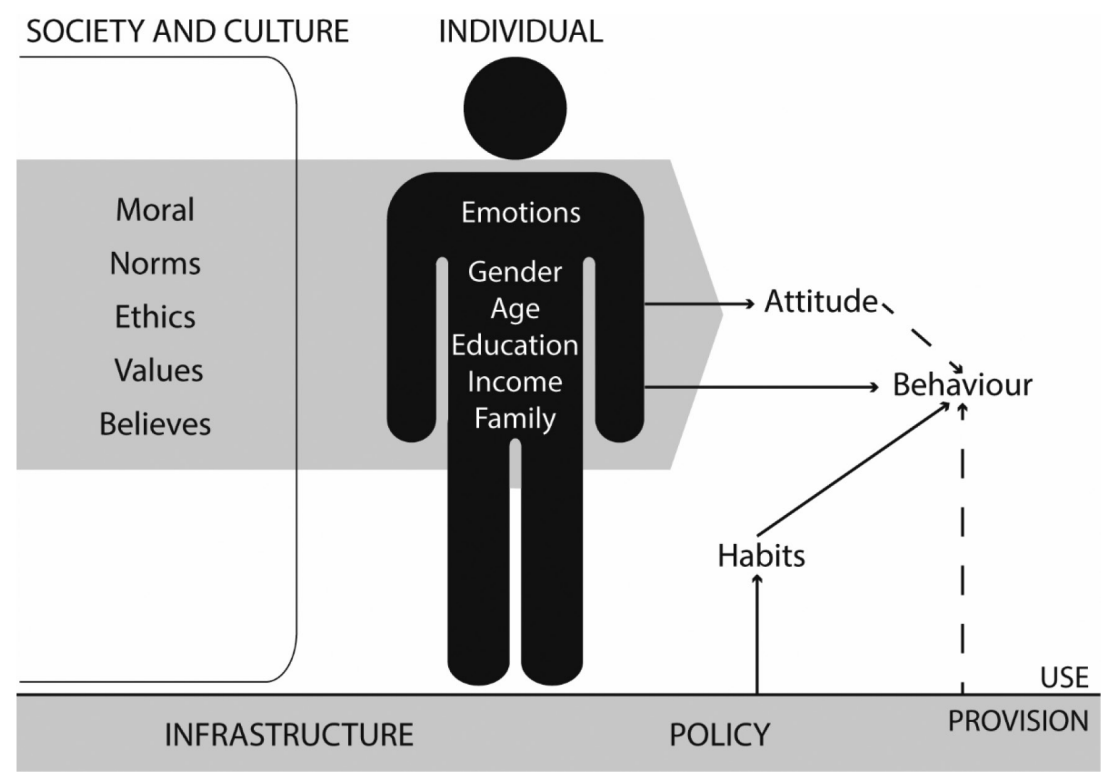

Figure 5: Proposed integrated and dynamic model of affecting behaviour through urban disciplines as well as through addressing community and personal aspects (authors).

sufficient in changing community's and the individual's behaviour. They must gain an understanding of the importance of different factors for individual decision-making and based on this adjust strategies and their implementation.

While it is possible and fruitful to cooperate with other disciplines that have greater awareness for such decision-making processes (such as environmental psychology, sociology, communication theory, social marketing, etc.), we also find that an extension of urban planning, urban design and urban policy to incorporate such sociological and psychological knowledge and understanding is useful. Thus, multi-disciplinary is necessary professionally, while urban sustainability theory and research must be extended to include and integrate such interdisciplinary fields.

So, when designing and proposing urban sustainability strategies, an increased awareness for individual behaviour change as well as its crucial factors needs to become common. As Jenks \& Dempsey state “it is behaviour, lifestyles and peoples' aspirations that are at the heart of achieving a sustainable environment" [39].

\subsection{Methodological implications}

The proposed twofold framework also has methodological implications. "With no clear rules that can be generally applied, local authorities need clear guidance and methods to assess the consequences of adopting different development strategies" [17]. For assessment and monitoring for instance, this means that there need to be several methods recording both infrastructure and policies, as well as recording individual choice and their motivation and intention. Over time, this will lead to a better understanding of which infrastructural change, policy change and other factors lead to successful implementation and resulting adoption of sustainable behaviour. However, as mentioned earlier, time as a relevant aspect should not be underestimated, as it seems to be the 
case that particular large-scale behaviour change (social and cultural) depends on a certain establishing phase.

Both infrastructure and policy need to be assessed with the help of indicator systems. Criteria for good indicators revolve around a clear definition, data availability, measurability, data quality, understandability, change sensitivity, policy relevance, implementability and accuracy in order to evaluate the context and success of projects [40-42]. In addition, they must be regularly updated, since the purpose of indicators is to monitor change, give early warnings, set targets, review performance and give information, communicate about the implemented strategy [43]. However, "the whole issue of indicators is a dynamic one" and "indicators will need to be revised in response to changing circumstances, and as our knowledge develops" [42]. It is therefore also recommended to use a mixture between objective and subjective indicators [44].

Collective behaviour can be documented in large-scale surveys, as is for instance the case for travel surveys. It is also possible to register collective travel behaviour through ICT systems, as is already the case for instance in public transport or through road toll systems. Here, a large amount of data are generated that can prove a rather holistic picture of urban travel behaviour. This big data can give information regarding the amount of people choosing to behave in certain ways. Depending on the used methodology, there is little information shedding light on motivation, intention and reasons for the displayed behaviour. Thus, personal choice needs are explored and registered through individual questionnaires and interviews. Particularly when interest is on motivation for behaviour (i.e. which factors lead to display behaviour) interviews might be advisable. However, like any self-reported information, such data can be flawed by social desirability and lack of knowledge (memory, etc.).

Another important point is to address the issue of choice and decision-making on all levels of the urban system. Just like for infrastructural and political issues, not only single communities should be addressed but the city or urban region needs to be seen as a whole. Raising awareness for behavioural aspects within planning professions, can help to ensure that the individuals choice as well as communication aspects become an integral part of urban development on all levels.

In order to be able to gain a greater understanding of the relation and interaction between infrastructure, policy and behaviour, it is necessary to study the implementation of urban sustainability strategies in-depth, from a holistic point of view and preferably over time.

Stavanger region, for instance, is undergoing some large scale changes, both with regards to public transport infrastructure and transport policy. County council Rogaland together with the Norwegian National Public Road Administration (NPRA) [Statens vegvesen] are currently planning 'Bussway 2020' [45]: $45 \mathrm{~km}$ of bus-only lanes that allow public transport to run smoothly through traffic congestions, according to the model of Luzern, Leeds and Bristol. The project will be finished in 2021 and 55 new high frequency and environmentally friendly busses will run on those lanes. They are also planning a 'bicycle highway' [sykkelstamvei] that runs parallel to the motorway, connecting the city centre with one of the largest work place concentrations in the region. In support of these infrastructural interventions, a new system of collecting road toll [Bypakke Nord-Jæren] is introduced [46], that targets commuting centres and operates with double prices during peak-hours. All these projects are planned to be finished and working within the next five years.

These projects are unique in a Norwegian context and offer great research opportunities. We therefore propose a holistic assessment and monitoring longitude-study, collecting 
reference data before project implementation, and then or several datasets to compare changes after project implementation. In order to gain knowledge about behavioural changes and their actual reasons it is advisable to retrieve data from one or several closed sample (for instance travel habits within certain companies). On the other hand, it might also be useful to record socio-cultural changes regarding the popularity and status of the projects over time. This can be done both based on newspaper reviews, survey or interviews. While it is too early to propose a concrete research approach, it is obvious that the implementation of these urban projects represents tremendous research opportunities.

Therefore, assessment and monitoring methods for urban sustainability strategies also need to incorporate an increased awareness for individual behaviour and its factors.

\section{DISCUSSION}

This paper covers a series of observations and reviews that lead to a better understanding of the urban sustainability concept and its reluctant implementation on one hand, as well as a deeper understanding for the meaning of individual behaviour change and its factors on the other hand. We have also briefly discussed theoretical and ideological implications of our observations for urban planning and policy disciplines, as well as possible research applications of the represented principles.

The presentation of inconsistencies does not necessarily warrant for solutions. However, raised awareness in addition to continued research into the topic might be able to alleviate some of the issues that were pointed out and cause continuously slow and reluctant realisation and achievement of urban sustainability.

Further, an increased focus on individual behaviour and behaviour change as the key to implementing urban sustainability strategies is important. Not only can it ensure more tailored strategies it might also create an increased focus on communicating the strategies to final users and, thus, install a sense of responsibility and ownership in the urban population.

Finally, there are some theoretical and methodological implications that have so far been undercommunicated. We hope that this paper offers a basis for continued interest and research into the topic of behavioural change and its factors in relationship to urban projects.

This paper is based on the conference paper Müller-Eie, D. \& Bjørnø, L., "Urban sustainability as social innovation" WIT Transactions on Ecology and the Environment, Vol 191, WIT Press, 2015, ISSN 1743-3541. It also refers to Müller-Eie, D. \& Bjørnø, L., "Urban sustainability and individual behavior" WIT Transactions on the Built Environment, Vol 168, WIT Press, 2015, ISSN 1743-3509.

\section{REFERENCES}

[1] Müller-Eie, D. \& Bjørnø, L., Urban sustainability as social innovation. WIT Transactions on Ecology and the Environment, 191, WIT Press, 2015, ISSN 17433541.

[2] Müller-Eie, D. \& Bjørnø, L., Urban sustainability and individual behavior. WIT Transactions on the Built Environment, 168, WIT Press, 2015, ISSN 1743-3509.

[3] Redclift, M., Sustainable development (1987-2005): an oxymoron comes of age. Sustainable Development, 13(4), pp. 212-227, 2005. http://dx.doi.org/10.1002/sd.281

[4] Anable, J., Lane, B. \& Kelay, T., An Evidence Base Review of Public Attitudes to Climate Change and Transport Behaviour, The Department for Transport, 2006. 
[5] Williams, K., Does intensifying cities make them more sustainable? In Achieving Sustainable Urban Form, eds K. Williams, E. Burton \& M. Jenks, E \& FN Spon: London, 2000.

[6] Welbank, M., The search for a sustainable urban form. In The Compact City: A Sustainable Urban Form? eds M. Jenks, E. Burton \& K. Williams, E \& FN Spon: London, 1996.

http://dx.doi.org/10.4324/9780203362372_the_search_for_a_sustainable_urban

[7] Breheny, M., The compact city and transport energy consumption. Transaction Institute of British Geographers, 20, pp. 81-101, 1995.

http://dx.doi.org/10.2307/622726

[8] Hillman, M., In favour of the compact city. In The Compact City - A Sustainable Urban Form? eds M. Jenks, E. Burton \& K. Williams, E \& FN Spon: London, 1996. http://dx.doi.org/10.4324/9780203362372_in_favour_of_the_compact_city

[9] Davidson, S., Up-scaling social behaviour change programmes: the case of ecoteams. In Engaging the Public with Climate Change: Behaviour Change and Communication, eds L. Whitmarsh, S. O’Neill \& I. Lorenzoni, Earthscan: London, 2011.

[10] Weber, C. \& Perrels, A., Modelling lifestyle effects on energy demand and related emissions. Energy Policy, 28, pp. 549-566, 2000.

http://dx.doi.org/10.1016/S0301-4215(00)00040-9

[11] Ben-Akiva, M. \& Bierlaire, M., Discrete choice methods and their applications to short term travel decisions. In Handbook of Transportation Science, Springer, pp. 5-33, 1999. http://dx.doi.org/10.1007/978-1-4615-5203-1_2

[12] Barrett, G., The transport dimension. In The Compact City: a Sustainable Urban Form? eds M. Jenks, E. Burton \& K. Williams, E \& FN Spon: London, 1996. http://dx.doi.org/10.4324/9780203362372_the_transport_dimension

[13] Schelling, T.C., Micromotives and Macrobehavior, New York: W.W. Norton \& Company, 1978.

[14] Lane, B. \& Potter, S., The adoption of cleaner vehicles in the UK: exploring the consumer attitude-action gap. Journal of Cleaner Production, 15(11-12), pp. 1085-1092, 2007. http://dx.doi.org/10.1016/j.jclepro.2006.05.026

[15] Næss, P., Can urban development be made environmentally sound? Journal of Environmental Planning and Management, 36(3), pp. 309-333. http://dx.doi.org/10.1080/09640569308711949

[16] Owens, S. \& Drifill, L., How to change attitudes and behaviours in the context of energy. Energy Policy, 36, pp. 4415-4418, 2008. http://dx.doi.org/10.1016/j.enpol.2008.09.031

[17] Hertwich, E.G., Life cycle approaches to sustainable consumption - a critical review. Environmental Science \& Technology, 39(13), pp. 4673-4684, 2005. http://dx.doi.org/10.1021/es0497375

[18] Knight, C., Economic and social issues. In the Compact City: A Sustainable Urban Form? eds M. Jenks, E. Burton \& K. Williams, E \& FN Spon: London, 1996.

[19] Ornetzeder, M., Hertwich, E.G., Hubacek, K., Korytarova, K. \& Haas, W., The environmental effect of car-free housing: A case in Vienna. Ecological Economics, 65, pp. 516-530, 2007. http://dx.doi.org/10.1016/j.ecolecon.2007.07.022 
[20] Williams, K., Dair, C. \& Lindsay, M., Neighbourhood design and sustainable lifestyles. In Dimensions of the Sustainable City, eds M. Jenks \& C. Jones, Springer: Dordrecht, 2010.

[21] Müller-Eie, D., Urban environmental performance and individual behaviour: a comparison between freiburg and stavanger. In Glasgow School of Art: Mackintosh School of Architecture, University of Glasgow: Glasgow, 2012.

[22] Bourdieu, P., The forms of capital.(1986). Cultural Theory: An Anthology, pp. 81-93, 2011.

[23] Rogers, E.M., Diffusion and Innovation, 5 edn., New York: Free Press, 2003.

[24] Triandis, H.C., Interpersonal Behavior, Brooks/Cole Publishing Company Monterey, CA, 1977.

[25] Lindenberg, S. \& Steg, L., Normative, gain and hedonic goal frames guiding environmental behavior. Journal of Social Issues, 63(1), pp. 117-137, 2007. http://dx.doi.org/10.1111/j.1540-4560.2007.00499.x

[26] Schuitema, G., Anable, J., Skippon, S. \& Kinnear, N., The role of instrumental, hedonic and symbolic attributes in the intention to adopt electric vehicles. Transportation Research Part A: Policy and Practice, 48, pp. 39-49, 2013. http://dx.doi.org/10.1016/j.tra.2012.10.004

[27] Steg, L., Car use: lust and must. Instrumental, symbolic and affective motives for car use. Transportation Research Part A: Policy and Practice, 39(2-3), pp. 147-162, 2005. http://dx.doi.org/10.1016/j.tra.2004.07.001

[28] Schwartz, S.H., Normative influences on altruism. Advances in Experimental Social Psychology, 10, pp. 221-279, 1977. http://dx.doi.org/10.1016/S0065-2601(08)60358-5

[29] Stern, P.C., Dietz, T., Abel, T.D., Guagnano, G.A. \& Kalof, L., A value-belief-norm theory of support for social movements: The case of environmentalism. Human Ecology Review, 6(2), pp. 81-98, 1999.

[30] Gauzin-Müller, D., Sustainable Architecture and Urbanism - Concepts, Technologies, Examples, Basel: Birkhäuser, 2002.

[31] Brannigan, F., Dismantling the consumption-happiness myth: A neuropsychological perspective on the mechanisms that lock us in to unsustainable consumption. In Engaging the Public with Climate Change: Behaviour Change and Communication, eds L. Whitmarsh, S. O'Neill \& I. Lorenzoni, Earthscan: London, 2011.

[32] Whitmarsh, L., O’Neill, S. \& Lorenzoni, I. (eds), Engaging the Public with Climate Change: Behaviour Change and Communication, Earthscan: London, 2014.

[33] Huijts, N.M.A., Molin, E.J.E. \& Steg, L., Psychological factors influencing sustainable energy technology acceptance: A review-based comprehensive framework. Renewable and Sustainable Energy Reviews, 16(1), pp. 525-531, 2012.

http://dx.doi.org/10.1016/j.rser.2011.08.018

[34] Schwanen, T., Banister, D. \& Anable, J., Rethinking habits and their role in behaviour change: the case of low-carbon mobility. Journal of Transport Geography, 24, pp. 522-532, 2012. http://dx.doi.org/10.1016/j.jtrangeo.2012.06.003

[35] Verplanken, B., Old habits and new routes to sustainable behaviour. In Engaging the Public with Climate Change: Behaviour Change and Communication, eds L. Whitmarsh, S. O’Neill \& I. Lorenzoni, Earthscan: London, 2011. 
[36] Burgess, J., Harrison, C.M. \& Filius, P., Environmental Communication and the Cultural Politics of Environmental Citizenship, 1998.

[37] Ajzen, I., The theory of planned behavior. Organizational Behavior and Human Decision Processes, 50(2), pp. 179-211, 1991. http://dx.doi.org/10.1016/0749-5978(91)90020-T

[38] Anable, J. \& Gatersleben, B., All work and no play? The role of instrumental and affective factors in work and leisure journeys by different travel modes. Transportation Research Part A: Policy and Practice, 39(2-3), pp. 163-181, 2005. http://dx.doi.org/10.1016/j.tra.2004.09.008

[39] Jenks, M. \& Dempsey, N. (eds), Future Forms and Design for Sustainable Cities, Elsevier: Amsterdam, XIII, 2005.

[40] Keirstead, J. \& Leach, M., Bridging the gaps between theory and practice: a service niche approach to urban sustainability indicators. Sustainable Development, 16, pp. 329-340, 2008. http://dx.doi.org/10.1002/sd.349

[41] Brohmann, B., Fritsche, U., Hartard, S., Schmied, M., Schmitt, B., Schünfelder, C., Schütt, N., Roos, W., Stahl, H., Timpe, C. \& Wiegmann, K., Nachhaltige Stadtteile auf innerstädtischen Konversionsfächen: Stoffstromanalyse als Bewertungsinstrument, Öko-Institut: Darmstadt/Freiburg/Berlin, 2002.

[42] Tate, J., Void dwellings - a 'headline' indicator? Sustainable Development, 10, pp. 36-50, 2002. http://dx.doi.org/10.1002/sd.176

[43] Alberti, M., Measuring urban sustainability. Environmental Impact Assessment Review, 16, pp. 381-424, 1996. http://dx.doi.org/10.1016/S0195-9255(96)00083-2

[44] Adolphe, L., A design tool for global evaluation of urban sustainability. In PLEA Environmentally Friendly, James \& James Science Publishers: Lisbon, 1998.

[45] County Council, R., Bussvei 2020. 2014 20.03.2015], available at: http://www.rogfk.no/ Vaare-tjenester/Samferdsel/Bussvei-20202.

[46] County Council, R., Bypakke Nord-Jacren. 2014 20.03.2015]; available at: http://www. rogfk.no/Vaare-tjenester/Samferdsel/Bypakke-Nord-Jaeren. 